Maltepe Journal of Mathematics

ISSN: 2667-7660, URL: HTTPS://DERGIPARK.ORG.TR/TR/PUB/MJM

Volume II Issue 2 (2020), Pages 43-54.

DOI: $10.47087 /$ MJM. 549174

\title{
A CLASS OF THIRD-ORDER BOUNDARY VALUE PROBLEM WITH INTEGRAL CONDITION AT RESONANCE
}

\author{
NOUREDDINE BOUTERAA* AND SLIMANE BENAICHA** \\ *LABORATORY OF FUNDAMENTAL AND APPLIED MATHEMATICS OF ORAN \\ (LMFAO), UNIVERSITY OF ORAN 1, AB, 31000, ALGERIA \\ **LABORATORY OF FUNDAMENTAL AND APPLIED MATHEMATICS OF ORAN \\ (LMFAO), UNIVERSITY OF ORAN 1, AB, 31000, ALGERIA
}

\begin{abstract}
In this paper, we consider third-order boundary value problem with, Dirichlet, Neumann and integral conditions at resonance case, where the kernel's dimension of the ordinary differential operator is equal to one and the ordinary differential equation which can be written as the abstract equation $L u=N u$, called semilinear form, where $L$ is a linear Fredholm operator of index zero, and $N$ is a nonlinear operator. First, we prove a priori estimates, and then we use Mawhin's coincidence degree theory to deduce the existence of solutions. One important ingredient to be able to apply this abstract results (Mawhin's coincidence degree theory) is proving the Fredholm property of the operator L. An example is also presented to illustrate the effectiveness of the main results.
\end{abstract}

\section{INTRODUCTION}

In this paper, we consider the following nonlinear third-order boundary value problem

$$
\begin{gathered}
u^{\prime \prime \prime}(t)=f\left(t, u(t), u^{\prime}(t), u^{\prime \prime}(t)\right), t \in(0,1), \\
u(0)=u^{\prime}(0)=0, u(1)=\frac{3}{\eta^{3}} \int_{0}^{\eta} u(t) d t, \eta \in(0,1),
\end{gathered}
$$

where $f:[0,1] \times \mathbb{R}^{3} \rightarrow \mathbb{R}$ is a continuous function, and $\eta \in(0,1)$. We say that the boundary value problem $1.1-1.2$ is a resonance problem if the linear equation $L u=u^{\prime \prime \prime}=0$, with the boundary value conditions 1.2 has non-trivial solution i.e. $\operatorname{dim} K \operatorname{erL} \geq 1$.

The theory of the boundary value problems with integral boundary conditions arises in different areas of applied mathematics and physics. For example, heat

2020 Mathematics Subject Classification. Primary: 34B10 ; Secondaries: 34B15 .

Key words and phrases. Resonance, Coincidence degree theory, Fredholm operator, One dimensional kernels, Nonlocal boundary value problem.

(C) 2020 Maltepe Journal of Mathematics.

Submitted: April 04 th, 2019. Published: October 30th, 2020.

Communicated by Valéria Neves DOMINGOS CAVALCANTI, and İdris DAĞ. 
conduction, chemical engineering, underground water flow, thermo-elasticity and plasma physics can be reduced to the nonlocal problems with integral boundary conditions. Recently, several authors have studied nonlocal boundary value problems at resonance and non-resonance for second-order, third-order and higherorder (in particular, third-order) ordinary differential equations, for instance see $[2,3,5,6,8,12,14,16,18,19,21]$ and the references therein. However, to our knowledge the corresponding results for third-order with integral boundary conditions are rarely seen $[1,7,9,10,11,15,17,20,22]$ and the references therein. In the most papers mentioned above, the coincidence degree theory of Mawhin was applied to establish existence theorem.

Inspired and motivation by works mentioned above, in the present article, we use the coincidence degree theory of Mawhin [13] to discuss the existence of solution for third-order nonlocal boundary value problem $\sqrt{1.1}-(1.2)$ at resonance case, and establish an existence theorem. The paper is organized as follows. In Section 2 we give the background information from coincidence degree theory, we also define appropriate mappings and projectors that will be used in the sequel. We state and prove our main result in Section 3, and we give an example to illustrate Theorem 3.1.

\section{Preliminaries}

We first recall some notations and an abstract existence result (Mawhin 1979). Let $Y, Z$ be two real Banach spaces and let $L: \operatorname{dom} L \subset Y \rightarrow Z$ be a linear operator which is Fredholm map of index zero (that is, $I m L$, the image of $L$, $\operatorname{Ker} L$, the kernel of $L$ is finite dimensional with the same dimension as the $Z / \operatorname{ImL})$, and $P: Y \rightarrow Y, Q: Z \rightarrow Z$ be continuous projections such that $\operatorname{Im} P=\operatorname{Ker} L, \operatorname{Ker} Q=\operatorname{Im} L$ and $Y=\operatorname{Ker} L \oplus \operatorname{Ker} P, Z=\operatorname{Im} L \oplus \operatorname{Im} Q$. It follows that $\left.L\right|_{\text {dom } L \cap K e r P} \rightarrow \operatorname{Im} L$ is invertible, we denote the inverse of that map by $K_{P}$. Let $\Omega$ be an open bounded subset of $Y$ such that $\operatorname{dom} L \cap \Omega \neq \phi$, the map $N: Y \rightarrow Z$ is said to be $L$ - compact on $\bar{\Omega}$ if the map $Q N: \bar{\Omega} \rightarrow Z$ is bounded and $K_{P}(I-Q) N: \bar{\Omega} \rightarrow Y$ is compact.

We will formulate the boundary value problem $1.10-(1.2)$ as $L u=N u$ where $L$ and $N$ are appropriate operators. To obtain our existence results we use the following fixed point theorem of Mawhin.

Theorem 2.1. (See [13]) Let $L$ be a Fredholm operator of index zero and $N$ be $L-$ compact on $\bar{\Omega}$. Assume that the following conditions are satisfied:

(i) $L u \neq \lambda N u$ for every $(u, \lambda) \in[(\operatorname{dom} L \backslash \operatorname{Ker} L) \cap \partial \Omega] \times(0,1)$.

(ii) $N u \notin I m L$ for every $u \in \operatorname{Ker} L \cap \partial \Omega$.

(iii) $\operatorname{deg}\left(\left.Q N\right|_{\text {KerL } L}, \Omega \cap \operatorname{Ker} L, 0\right) \neq 0$,

where $Q: Z \rightarrow Z$ is a projection as above with $\operatorname{ImL}=\operatorname{Ker} Q$.

Then the abstract equation $L u=N u$ has at least one solution in $\operatorname{dom} L \cap \bar{\Omega}$.

In the following, we shall use the classical spaces $C[0,1], C^{1}[0,1], C^{2}[0,1]$ and $L^{1}[0,1]$. For $u \in C^{2}[0,1]$, we use the norm $\|u\|=\max \left\{\|u\|_{\infty},\left\|u^{\prime}\right\|_{\infty},\left\|u^{\prime \prime}\right\|_{\infty}\right\}$ where $\|u\|_{\infty}=\max _{t \in[0,1]}|u(t)|$ and denote the norm in $L^{1}[0,1]$ by $\|\cdot\|_{1}$.

We will use the Sobolev space $W^{3,1}(0,1)$ which is defined by

$W^{3,1}(0,1)=\left\{u:[0,1] \rightarrow \mathbb{R}: u, u^{\prime}, u^{\prime \prime}\right.$ are absolutely continuous on $[0,1]$ with $\left.u^{\prime \prime \prime} \in L^{1}[0,1]\right\}$. 
Let $Y=C^{2}[0,1], Z=L^{1}[0,1]$, define the linear operator $L: \operatorname{dom} L \subset Y \rightarrow Z$ by

$$
L u=u^{\prime \prime \prime}, \quad u \in \operatorname{dom} L,
$$

where

$$
\operatorname{dom} L=\left\{u \in W^{3,1}(0,1): u(0)=u^{\prime}(0)=0, u(1)=\frac{3}{\eta^{3}} \int_{0}^{\eta} u(t) d t\right\},
$$

and define $N: Y \rightarrow Z$ by

$$
N u(t)=f\left(t, u(t), u^{\prime}(t), u^{\prime \prime}(t)\right), t \in(0,1) .
$$

Then the boundary value problem $11.1-1.2$ can be written as $L u=N u$.

\section{EXISTENCE RESUlts}

We will assume that the following conditions hold and in all this paper let us set

$$
\begin{aligned}
R f\left(s, u(s), u^{\prime}(s), u^{\prime \prime}(s)\right) & =\int_{0}^{1}(1-s)^{2} f\left(s, u(s), u^{\prime}(s), u^{\prime \prime}(s)\right) d s \\
& -\frac{1}{\eta^{3}} \int_{0}^{\eta}(\eta-s)^{3} f\left(s, u(s), u^{\prime}(s), u^{\prime \prime}(s)\right) d s .
\end{aligned}
$$

$\left(H_{1}\right)$ There exist functions $\alpha, \beta, \gamma, r \in L^{1}[0,1]$, such that for $(u, v, w) \in \mathbb{R}^{3}, t \in$ $[0,1]$, it holds

$$
|f(t, u, v, w)| \leq \alpha(t)|u|+\beta(t)|v|+\gamma(t)|w|+r(t) .
$$

$\left(H_{2}\right)$ There exists a constant $M>0$ such that for $u \in \operatorname{dom} L$, if $\left|u^{\prime \prime}(t)\right|>M$ for all $t \in[0,1]$, then

$$
R f\left(s, u(s), u^{\prime}(s), u^{\prime \prime}(s)\right) \neq 0 .
$$

$\left(H_{3}\right)$ There exists a constant $M^{*}>0$ such that for any $u(t)=\frac{b}{2} t^{2} \in \operatorname{Ker} L$ with $\left|\frac{b}{2}\right|>M^{*}$, either

$$
\frac{b}{2}\left[R f\left(s, u(s), u^{\prime}(s), u^{\prime \prime}(s)\right)\right]<0,
$$

or else

$$
\frac{b}{2}\left[R f\left(s, u(s), u^{\prime}(s), u^{\prime \prime}(s)\right)\right]>0 .
$$

Theorem 3.1. Let $f:[0,1] \times \mathbb{R}^{3} \rightarrow \mathbb{R}$ be a continuous function, assume that conditions $\left(H_{1}\right)-\left(H_{3}\right)$ hold and that

$$
\|\alpha\|_{1}+\|\beta\|_{1}+\|\gamma\|_{1}<\frac{1}{2} .
$$

Then the boundary value problem 1.1 - 1.2 has at least one solution in $C^{2}[0,1]$. 
For the Proof of Theorem 3.1 we shall apply Theorem 2.1 and the following Lemmas. Before we state our lemmas, we say that $L$ is a Fredholm operator of index zero, that is, $\operatorname{ImL}$ is closed and $\operatorname{dim} \operatorname{Ker} L=\operatorname{codim} \operatorname{ImL}$. This implies that there exist a continuous projections $P: Y \rightarrow Y$ and $Q: Z \rightarrow Z$ such that $\operatorname{Im} P=\operatorname{Ker} L$ and $\operatorname{Ker} Q=\operatorname{Im} L$. For this purpose, we must define $P$ by (3.1) (see later), the linear continuous projector operator $Q$ by

$$
Q y(t)=\frac{1}{C}\left[\int_{0}^{1}(1-s)^{2} y(s) d s-\frac{1}{\eta^{3}} \int_{0}^{\eta}(\eta-s)^{3} y(s) d s\right] t^{2},
$$

where $\frac{1}{C}=\frac{60}{2-\eta^{3}}$ and the linear operator $K_{P}: \operatorname{Im} L \rightarrow \operatorname{dom} L \cap \operatorname{KerP}$ by

$$
K_{P} y(t)=\frac{1}{2} \int_{0}^{t}(t-s)^{2} y(s) d s, \quad \forall y \in \operatorname{ImL} .
$$

Lemma 3.2. (i) The operator $L:$ dom $L \subset Y \rightarrow Z$ is a Fredholm operator of index zero.

(ii) For every $y \in \operatorname{ImL}$, we have

$$
\left\|K_{P} y\right\| \leq\|y\|_{1}
$$

Proof. First, we prove $(i)$. It is clear that

$$
\begin{aligned}
\operatorname{Ker} L & =\{u \in \operatorname{dom} L: L u=0\} \\
& =\left\{u \in \operatorname{dom} L: u^{\prime \prime \prime}=0\right\} \\
& =\left\{u \in \operatorname{dom} L: u(t)=\frac{b}{2} t^{2}, b \in \mathbb{R}\right\} \simeq \mathbb{R} .
\end{aligned}
$$

Now, we show that

$$
\operatorname{Im} L=\left\{y \in Z: \int_{0}^{1}(1-s)^{2} y(s) d s-\frac{1}{\eta^{3}} \int_{0}^{\eta}(\eta-s)^{3} y(s) d s=0\right\} .
$$

In fact

$$
u^{\prime \prime \prime}=y,
$$

has a solution $u(t)$ that satisfies the boundary value conditions 1.2 , if and only if

$$
\int_{0}^{1}(1-s)^{2} y(s) d s-\frac{1}{\eta^{3}} \int_{0}^{\eta}(\eta-s)^{3} y(s) d s=0
$$

From (3.7), we have

$$
u(t)=u(0)+u^{\prime}(0) t+u^{\prime \prime}(0) \frac{t^{2}}{2}+\frac{1}{2} \int_{0}^{t}(t-s)^{2} y(s) d s .
$$

Thus from the condition $u(0)=u^{\prime}(0)=0$, we have

$$
u(t)=u^{\prime \prime}(0) \frac{t^{2}}{2}+\frac{1}{2} \int_{0}^{t}(t-s)^{2} y(s) d s .
$$


According to $u(1)=\frac{3}{\eta^{3}} \int_{0}^{\eta} u(t) d t$, we have

$$
\frac{1}{2} u^{\prime \prime}(0)+\frac{1}{2} \int_{0}^{1}(1-s)^{2} y(s) d s=\frac{3}{\eta^{3}}\left[\int_{0}^{\eta} u^{\prime \prime}(0) \frac{t^{2}}{2} d t+\frac{1}{2} \int_{0}^{\eta} \int_{0}^{t}(t-s)^{2} y(s) d s d t\right] \text {, }
$$

i.e.

$$
\int_{0}^{1}(1-s)^{2} y(s) d s-\frac{1}{\eta^{3}} \int_{0}^{\eta}(\eta-s)^{3} y(s) d s=0 .
$$

Hence

$$
\operatorname{Im} L=\left\{y \in Z: \int_{0}^{1}(1-s)^{2} y(s) d s-\frac{1}{\eta^{3}} \int_{0}^{\eta}(\eta-s)^{3} y(s) d s=0\right\} .
$$

On the other hand, if (3.8) holds, setting

$$
u(t)=\frac{b}{2} t^{2}+\frac{1}{2} \int_{0}^{t}(t-s)^{2} y(s) d s
$$

where $b$ is an arbitrary constant, then $u(t)$ is a solution of (3.7). Hence (3.6) holds. For simplicity of notation in the definition of the projector operator $Q$, we set

$$
R y=\int_{0}^{1}(1-s)^{2} y(s) d s-\frac{1}{\eta^{3}} \int_{0}^{\eta}(\eta-s)^{3} y(s) d s .
$$

Let $C=\int_{0}^{1}(1-t)^{2} t^{2} d t-\frac{1}{\eta^{3}} \int_{0}^{\eta}(\eta-t)^{3} t^{2} d t \neq 0, t \in(0,1]$. By simple calculation, we get $C=\frac{2-\eta^{3}}{60}$.

Now, we need to show that the operator $Q$ is projector. From $Q y(t)=\frac{1}{C} \cdot(R y) \cdot t^{2}$, we have

$$
\begin{aligned}
\left(Q^{2} y\right)(t) & =(Q(Q y))(t), \\
& =\frac{1}{C}\left(\frac{1}{C} R y\right)\left(\int_{0}^{1}(1-t)^{2} t^{2} d s-\frac{1}{\eta^{3}} \int_{0}^{\eta}(\eta-t)^{3} t^{2} d s\right) t^{2}, \\
& =\frac{1}{C}(R y) t^{2} \\
& =(Q y)(t),
\end{aligned}
$$

which implies that the operator $Q$ is a projector. Furthermore, $\operatorname{Im} L=\operatorname{Ker} Q$.

In order, to show $Z=\operatorname{Im} L \oplus \operatorname{Im} Q$, it remains to shows two following steps.

Step 1. For $y \in Z$, let $y=(y-Q y)+Q y$, since $Q(y-Q y)=Q y-Q^{2} y=0$, we know $(y-Q y) \in \operatorname{Ker} Q=\operatorname{ImL}$ and $Q y \in \operatorname{Im} Q$. Thus

$$
Z=\operatorname{Im} L+\operatorname{Im} Q \text {. }
$$

Step 2. Let $y \in \operatorname{Im} L \cap \operatorname{Im} Q$. Since $y \in \operatorname{Im} Q$, then there exists $\rho \in \mathbb{R}$ such that $y(t)=\rho t^{2}, t \in[0,1]$. Since $y \in \operatorname{ImL}=\operatorname{Ker} Q$, then

$$
0=\rho(R y)(t)=\rho\left(\int_{0}^{1}(1-t)^{2} t^{2} d s-\frac{1}{\eta^{3}} \int_{0}^{\eta}(\eta-t)^{3} t^{2} d s\right)=\rho C .
$$


Since $C \neq 0$, then $\rho=0$, so we have $y(t)=0, t \in[0,1]$, which implies

$$
\operatorname{Im} L \cap \operatorname{Im} Q=\{0\} .
$$

As consequence of Step 1 and Step 2, we deduce that

$$
Z=\operatorname{Im} L \oplus \operatorname{Im} Q,
$$

and so

$$
\operatorname{dim} \operatorname{Ker} L=\operatorname{codim} \operatorname{Im} L=\operatorname{dim} \operatorname{Im} Q=1 .
$$

Thus $L$ is Fredholm operator of index zero.

We are now ready to give the other projector employed in the proof of $(i i)$. Define $P: Y \rightarrow Y$ by

$$
(P u)(t)=u^{\prime \prime}(0) \frac{t^{2}}{2} \text {. }
$$

Note that $\operatorname{Ker} P=\left\{u \in Y: u^{\prime \prime}(0) \frac{t^{2}}{2}=0\right\}=\left\{u \in Y: u^{\prime \prime}(0)=0\right\}$ and $\operatorname{ImP}=$ $\operatorname{KerL}$.

Similarly, we shall prove that the operator $P$ is projector and $Y=\operatorname{Ker} P \oplus \operatorname{Ker} L$. Fistly, since $(P u)^{\prime \prime}(t)=u^{\prime \prime}(0)$, then $\left(P^{2} u\right)(t)=P u(t), t \in[0,1]$.

Secondly, for all $u \in Y$ and $t \in[0,1]$, we have

$$
\begin{aligned}
u(t) & =(u(t)-P u(t))+P u(t) \\
& =\left(u(t)-u^{\prime \prime}(0) \frac{t^{2}}{2}\right)+u^{\prime \prime}(0) \frac{t^{2}}{2},
\end{aligned}
$$

that is $Y=\operatorname{Ker} P+\operatorname{Ker} L$. By simple calculation we can get $\operatorname{Ker} L \cap \operatorname{Ker} P=\{0\}$. Then $Y=K \operatorname{Ker} P \oplus \operatorname{Ker} L$.

Before, to estimate the supremum norm of the generalized inverse operator $K_{P}$. It remains to prove that the operator $K_{P}$ is the generalized inverse of $L$. In fact, if $y \in \operatorname{ImL}$, then

$$
\left(L K_{P}\right) y(t)=\left[\left(K_{P} y\right)(t)\right]^{\prime \prime \prime}=y(t) .
$$

And for $u \in \operatorname{dom} L \cap \operatorname{Ker} P$, we know

$\left(K_{P} L\right) u(t)=\left(K_{P}\right) u^{\prime \prime \prime}(t)=\frac{1}{2} \int_{0}^{t}(t-s)^{2} u^{\prime \prime \prime}(s) d s=u(t)-u(0)-u^{\prime}(0) t-u^{\prime \prime}(0) \frac{t^{2}}{2}$,

in view of $u \in \operatorname{dom} L \cap \operatorname{Ker} P, u(0)=u^{\prime}(0)=0$ and $P u=0$, it follows that

$$
\left(K_{P} L\right) u(t)=u(t) .
$$

This shows that $K_{P}=\left(\left.L\right|_{\text {domL } L \text { KerP } P}\right)^{-1}$.

Lastly, we estimate the supremum norm of the generalized inverse operator $K_{P}$.

From the definition of $K_{P}$, it follows that

$$
\left\|K_{P} y\right\|_{\infty} \leq \frac{1}{2} \int_{0}^{1}(1-s)^{2}|y(s)| d s \leq \int_{0}^{1}|y(s)| d s=\|y\|_{1} .
$$

From $\left(K_{P} y\right)^{\prime}(t)=\int_{0}^{t}(t-s) y(s) d s$, we obtain

$$
\left\|\left(K_{P} y\right)^{\prime}\right\|_{\infty} \leq \int_{0}^{1}(1-s)|y(s)| d s \leq \int_{0}^{1}|y(s)| d s=\|y\|_{1},
$$


and from $\left(K_{P} y\right)^{\prime \prime}(t)=\int_{0}^{t} y(s) d s$, we obtain

$$
\left\|\left(K_{P} y\right)^{\prime \prime}\right\|_{\infty} \leq \int_{0}^{1}|y(s)| d s=\|y\|_{1},
$$

then

$$
\left\|K_{P} y\right\| \leq\|y\|_{1} .
$$

Lemma 3.3. Let $\Omega_{1}=\{u \in \operatorname{dom} L \backslash \operatorname{Ker} L: L u=\lambda N u$, for some $\lambda \in[0,1]\}$. Then $\Omega_{1}$ is bounded.

Proof. Suppose that $u \in \Omega_{1}$, and $L u=\lambda N u$. Thus $\lambda \neq 0$ and $Q N u=0$, so it yields

$$
R f\left(s, u(s), u^{\prime}(s), u^{\prime \prime}(s)\right)=0 .
$$

Thus, by condition $\left(H_{2}\right)$, there exists $t_{1} \in[0,1]$, such that $\left|u^{\prime \prime}\left(t_{1}\right)\right| \leq M$. In view of

$$
u^{\prime \prime}(0)=u^{\prime \prime}\left(t_{1}\right)-\int_{0}^{t_{1}} u^{\prime \prime \prime}(t) d t
$$

then, we have

$$
\left|u^{\prime \prime}(0)\right| \leq M+\int_{0}^{1}\left|u^{\prime \prime \prime}(s)\right| d s=M+\left\|u^{\prime \prime \prime}\right\|_{1}=M+\|L u\|_{1} \leq M+\|N u\|_{1} .
$$

Again for $u \in \Omega_{1}$, then $(I-P) u \in \operatorname{dom} L \cap K e r P=I m K_{P}$ and $L P u=0,0<\lambda<1$ and $N u=\frac{1}{\lambda} L u \in \operatorname{ImL}$, thus from Lemma 3.2 we know

$$
\|(I-P) u\|=\left\|K_{P} L(I-P) u\right\| \leq\|L(I-P) u\|_{1}=\|L u\|_{1} \leq\|N u\|_{1} .
$$

From (3.11), 3.12) and $\|P u\|=\left|u^{\prime \prime}(0)\right|$, we have

$$
\|u\| \leq\|P u\|+\|(I-P) u\|=\left|u^{\prime \prime}(0)\right|+\|(I-P) u\| \leq M+2\|N u\|_{1} .
$$

From (3.1) and (3.13), we obtain

$$
\|u\| \leq 2\left[\|\alpha\|_{1}\|u\|_{\infty}+\|\beta\|_{1}\left\|u^{\prime}\right\|_{\infty}+\|\gamma\|_{1}\left\|u^{\prime \prime}\right\|_{\infty}+\|r\|_{1}+\frac{M}{2}\right] .
$$

Thus, from $\|u\|_{\infty} \leq\|u\|$ and (3.14), we have

$$
\|u\|_{\infty} \leq \frac{2}{1-2\|\alpha\|_{1}}\left[\|\beta\|_{1}\left\|u^{\prime}\right\|_{\infty}+\|\gamma\|_{1}\left\|u^{\prime \prime}\right\|_{\infty}+\|r\|_{1}+\frac{M}{2}\right] .
$$

From $\left\|u^{\prime}\right\|_{\infty} \leq\|u\|$, (3.14) and (3.15), we have

i.e

$$
\begin{aligned}
\left\|u^{\prime}\right\|_{\infty} \leq\|u\|, \\
\left\|u^{\prime}\right\|_{\infty} \leq 2\left[1+\frac{2\|\alpha\|_{1}}{1-2\|\alpha\|_{1}}\right]\left[\|\beta\|_{1}\left\|u^{\prime}\right\|_{\infty}+\|\gamma\|_{1}\left\|u^{\prime \prime}\right\|_{\infty}+\|r\|_{1}+\frac{M}{2}\right], \\
=\frac{2}{1-2\|\alpha\|_{1}}\left[\|\beta\|_{1}\left\|u^{\prime}\right\|_{\infty}+\|\gamma\|_{1}\left\|u^{\prime \prime}\right\|_{\infty}+\|r\|_{1}+\frac{M}{2}\right]
\end{aligned}
$$

$$
\left\|u^{\prime}\right\|_{\infty}\left[\frac{1-2\|\alpha\|_{1}-2\|\beta\|_{1}}{1-2\|\alpha\|_{1}}\right] \leq \frac{2}{1-2\|\alpha\|_{1}}\left[\|\gamma\|_{1}\left\|u^{\prime \prime}\right\|_{\infty}+\|r\|_{1}+\frac{M}{2}\right] .
$$


Therefore

$$
\left\|u^{\prime}\right\|_{\infty} \leq \frac{2}{1-2\|\alpha\|_{1}-2\|\beta\|_{1}}\left[\|\gamma\|_{1}\left\|u^{\prime \prime}\right\|_{\infty}+\|r\|_{1}+\frac{M}{2}\right] .
$$

Again, from $\left\|u^{\prime \prime}\right\|_{\infty} \leq\|u\|,(3.14),(3.15)$ and (3.16), we have

$$
\begin{aligned}
\left\|u^{\prime \prime}\right\|_{\infty} & \leq\left[2\|\beta\|_{1}+\frac{4\|\beta\|_{1}\|\alpha\|_{1}}{1-2\|\alpha\|_{1}}\right]\left\|u^{\prime}\right\|_{\infty}+\left[\frac{4\|\alpha\|_{1}}{1-2\|\alpha\|_{1}}+2\right]\left[\|\gamma\|_{1}\left\|u^{\prime \prime}\right\|_{\infty}+\|r\|_{1}+\frac{M}{2}\right], \\
& \leq\left[\frac{4\|\beta\|_{1}}{\left(1-2\|\alpha\|_{1}-2\|\beta\|_{1}\right)\left(1-2\|\alpha\|_{1}\right)}+\frac{2}{1-2\|\alpha\|_{1}}\right]\left[\|\gamma\|_{1}\left\|u^{\prime \prime}\right\|_{\infty}+\|r\|_{1}+\frac{M}{2}\right], \\
& =\frac{2}{\left(1-2\|\alpha\|_{1}-2\|\beta\|_{1}\right)}\left[\|\gamma\|_{1}\left\|u^{\prime \prime}\right\|_{\infty}+\|r\|_{1}+\frac{M}{2}\right],
\end{aligned}
$$

i.e

$$
\left\|u^{\prime \prime}\right\|_{\infty} \leq\left[\frac{2\left(\|r\|_{1}+\frac{M}{2}\right)}{1-2\|\alpha\|_{1}-2\|\beta\|_{1}-2\|\gamma\|_{1}}\right],
$$

thus, from (3.17), there exists $M_{1}>0$ such that

$$
\left\|u^{\prime \prime}\right\|_{\infty} \leq M_{1}
$$

therefore, from (3.18) and (3.16), there exists $M_{2}>0$, such that

$$
\left\|u^{\prime}\right\|_{\infty} \leq M_{2}
$$

hence, from 3.19 and 3.15 , there exists $M_{3}>0$, such that

$$
\|u\|_{\infty} \leq M_{3} \text {. }
$$

Consequently

$$
\|u\|=\max \left\{\|u\|_{\infty},\left\|u^{\prime}\right\|_{\infty},\left\|u^{\prime \prime}\right\|_{\infty}\right\} \leq \max \left\{M_{1}, M_{2}, M_{3}\right\} .
$$

Again, from (3.1), 3.18), 3.19) and (3.20), we have

$$
\left\|u^{\prime \prime \prime}\right\|_{1}=\|L u\|_{1} \leq\|N u\|_{1} \leq\|\alpha\|_{1} M_{3}+\|\beta\|_{1} M_{2}+\|\gamma\|_{1} M_{1}+\|r\|_{1} .
$$

So, $\Omega_{1}$ is bounded.

Lemma 3.4. The set $\Omega_{2}=\{u \in \operatorname{KerL}: N u \in \operatorname{ImL}\}$ is bounded.

Proof. Let $u \in \Omega_{2}$, then $u \in \operatorname{Ker} L=\left\{u \in \operatorname{dom} L: u=\frac{b}{2} t^{2}, b \in \mathbb{R}, t \in[0,1]\right\}$. Also, since $\operatorname{Ker} Q=\operatorname{Im} L$, then $Q N u=0$, therefore

$$
R f\left(s, \frac{b}{2} s^{2}, b s, b\right)=0 .
$$

From condition $\left(H_{2}\right),\|u\|_{\infty}=\left|\frac{b}{2}\right| \leq M$, so $\|u\| \leq M$, thus $\Omega_{2}$ is bounded.

Before we define the set $\Omega_{3}$, we must state our isomorphism, $J: \operatorname{Ker} L \rightarrow \operatorname{Im} Q$. Let

$$
J\left(\frac{b}{2} t^{2}\right)=\frac{b}{2} t^{2}, \forall b \in \mathbb{R}, t \in[0,1],
$$

and define

$$
\Omega_{3}=\{u \in \operatorname{KerL}:-\lambda J u+(1-\lambda) Q N u=0, \lambda \in[0,1]\} .
$$


Lemma 3.5. If the first part of condition $\left(\mathrm{H}_{3}\right)$ holds, then

$$
\left(\frac{b}{2}\right)\left(\frac{60}{2-\eta^{3}}\right)\left[R f\left(s, \frac{b}{2} s^{2}, b s, b\right) d s\right]<0
$$

for all $\left|\frac{b}{2}\right|>M^{*}$ and $\Omega_{3}$ is bounded.

Proof. Suppose that $u=\frac{b_{0}}{2} t^{2} \in \Omega_{3}$. Then we obtain

$$
\lambda\left(\frac{b_{0}}{2}\right)=(1-\lambda)\left(\frac{60}{2-\eta^{3}}\right)\left(R f\left(s, b_{0} \frac{s^{2}}{2}, b_{0} s, b_{0}\right)\right) .
$$

If $\lambda=1$, then $b_{0}=0$, which gives $\Omega_{3}$ bounded.

Otherwise, if $\lambda \neq 1$, there exist $M^{*}>0$ such that $\left|\frac{b_{0}}{2}\right|>M^{*}$. Then in view of (3.21), we have

$$
\lambda\left(\frac{b_{0}}{2}\right)^{2}=(1-\lambda) \frac{b_{0}}{2}\left(\frac{60}{2-\eta^{3}}\right)\left(R f\left(s, b_{0} \frac{s^{2}}{2}, b_{0} s, b_{0}\right)\right)<0,
$$

which contradicts the fact that $\lambda\left(\frac{b_{0}}{2}\right)^{2} \geq 0$. Then $|u|=\left|\frac{b_{0}}{2} t^{2}\right| \leq\left|\frac{b_{0}}{2}\right| \leq M^{*}$, we obtain $\|u\| \leq M^{*}$. Hence $\Omega_{3} \subset\left\{u \in \operatorname{Ker} L:\|u\| \leq M^{*}\right\}$ is bounded.

If $\lambda=0$, it yields

$$
R f\left(s, \frac{b_{0}}{2} s^{2}, b_{0} s, b_{0}\right)=0 .
$$

Taking condition $\left(H_{2}\right)$ into account, we obtain $\|u\|=\left|\frac{b}{2}\right| \leq M^{*}$.

Now, define $\Omega_{3}$ by

$$
\Omega_{3}=\{u \in \operatorname{KerL}: \lambda J u+(1-\lambda) Q N u=0, \lambda \in[0,1]\}
$$

Lemma 3.6. If the second part of $\left(\mathrm{H}_{3}\right)$ holds, then

$$
\left(\frac{b}{2}\right)\left(\frac{60}{2-\eta^{3}}\right)\left[R f\left(s, \frac{b}{2} s^{2}, b s, b\right)\right]>0
$$

for all $\left|\frac{b}{2}\right|>M^{*}$ and $\Omega_{3}$ is bounded.

Proof. A similar argument as above shows that $\Omega_{3}$ is bounded.

The Proof of Theorem 3.1 is now an easy consequence of the above lemmas and Theorem 2.1.

Proof. of Theorem 3.1

Let $\Omega$ to be an open bounded subset of $Y$ such that $\bigcup_{i=1}^{3} \bar{\Omega}_{i} \subset \Omega$. By using the fact that $u^{\prime \prime \prime}$ is bounded and the Arzela-Ascoli Theorem, we can prove that $K_{P}(I-Q) N: \bar{\Omega} \rightarrow Y$ is compact, thus $N$ is $L$ - compact on $\bar{\Omega}$. Then by Lemmas 3.3 and 3.4 , we have

(i) $L u \neq \lambda N u$ for every $(u, \lambda) \in[(\operatorname{dom} L \backslash \operatorname{Ker} L) \cap \partial \Omega] \times(0,1)$.

(ii) $N u \notin I m L$ for every $u \in \operatorname{Ker} L \cap \partial \Omega$.

(iii) Let $H(u, \lambda)= \pm \lambda J u+(1-\lambda) Q N u=0, \lambda \in[0,1]$.

According to Lemmas 3.5 and 3.6 , we know that $H(u, \lambda) \neq 0$ for every $u \in \operatorname{Ker} L \cap$ $\partial \Omega$. Thus, by the homotopy property of degree, we obtain

$$
\begin{aligned}
\operatorname{deg}\left(\left.Q N\right|_{\text {KerL } L}, \Omega \cap \operatorname{KerL}, 0\right) & =\operatorname{deg}(H(\cdot, 0), \Omega \cap \operatorname{Ker} L, 0), \\
& =\operatorname{deg}(H(\cdot, 1), \Omega \cap \operatorname{Ker} L, 0),
\end{aligned}
$$


NOUREDDINE BOUTERAA AND SLIMANE BENAICHA

$$
=\operatorname{deg}( \pm J, \Omega \cap \operatorname{Ker} L, 0) \neq 0 .
$$

Then, by Theorem 2.1. $L u=N u$ has at least one solution in $\operatorname{dom} L \cap \bar{\Omega}$, so the boundary value problem $1.1-1.2$ has at least one solution in $C^{2}[0,1]$. The proof is complete.

We construct an example to illustrate the applicability of the results presented.

Example 3.1. Consider the following boundary value problem

$$
\begin{gathered}
u^{\prime \prime \prime}(t)=f\left(t, u(t), u^{\prime}(t), u^{\prime \prime}(t)\right), t \in(0,1), \\
u(0)=u^{\prime}(0)=0, u(1)=\frac{3}{\eta^{3}} \int_{0}^{\eta} u(t) d t, \eta \in(0,1),
\end{gathered}
$$

where

$$
f\left(t, u(t), u^{\prime}(t), u^{\prime \prime}(t)\right)=\frac{1}{3} u^{\prime \prime}(t)+\frac{1}{6}(1-t)\left(1-\cos \left(u^{\prime}(t)\right) \sin (u(t)), \quad t \in(0,1) .\right.
$$

Here we have

$$
\mid \frac{1}{3} u^{\prime \prime}(t)+\frac{1}{6}(1-t)\left(1-\cos \left(u^{\prime}(t)\right) \sin (u(t))\left|\leq \frac{1}{3}+\frac{1}{3}\right| u^{\prime \prime}(t) \mid,\right.
$$

that is

$$
\alpha(t)=0, \beta(t)=0, \gamma(t)=\frac{1}{3} \text { and } r(t)=\frac{1}{3} .
$$

So, condition $\left(H_{1}\right)$ is satisfied, which gives

Set

$$
\|\alpha\|_{1}+\|\beta\|_{1}+\|\gamma\|_{1}=\frac{1}{3}<\frac{1}{2}
$$

$I=R f\left(s, u(s), u^{\prime}(s), u^{\prime \prime}(s)\right)$

$$
=\int_{0}^{1}(1-s)^{2} f\left(s, u(s), u^{\prime}(s), u^{\prime \prime}(s)\right) d s-\frac{1}{\eta^{3}} \int_{0}^{\eta}(\eta-s)^{3} f\left(s, u(s), u^{\prime}(s), u^{\prime \prime}(s)\right) d s .
$$

If $u^{\prime \prime}(t)<-M=-10$, then

$$
f\left(t, u(t), u^{\prime}(t), u^{\prime \prime}(t)\right)<\frac{1}{3}(1-M)=-3<0 .
$$

In this case, we have $I<0$, because

$$
\int_{0}^{1}(1-s)^{2} f\left(s, u(s), u^{\prime}(s), u^{\prime \prime}(s)\right) d s<\int_{0}^{\eta}\left(1-\frac{s}{\eta}\right)^{3} f\left(s, u(s), u^{\prime}(s), u^{\prime \prime}(s)\right) d s .
$$

If $u^{\prime \prime}(t)>M=10$, then

$$
f\left(t, u(t), u^{\prime}(t), u^{\prime \prime}(t)\right)>\frac{1}{3}(1+M)=\frac{11}{3}>0 .
$$

Hence, $I>0$, because

$$
\int_{0}^{1}(1-s)^{2} f\left(s, u(s), u^{\prime}(s), u^{\prime \prime}(s)\right) d s>\int_{0}^{\eta}\left(1-\frac{s}{\eta}\right)^{3} f\left(s, u(s), u^{\prime}(s), u^{\prime \prime}(s)\right) d s .
$$


Therefore, the condition $\left(\mathrm{H}_{2}\right)$ is satisfied.

If $\frac{b}{2}<-M^{*}=-5$ and $u(t)=\frac{b}{2} t^{2}$, then

$$
f\left(t, u(t), u^{\prime}(t), u^{\prime \prime}(t)\right)<\frac{1}{3}(1+b)=-3<0 .
$$

In this case, we have $I<0$, because

$$
\int_{0}^{1}(1-s)^{2} f\left(s, u(s), u^{\prime}(s), u^{\prime \prime}(s)\right) d s<\int_{0}^{\eta}\left(1-\frac{s}{\eta}\right)^{3} f\left(s, u(s), u^{\prime}(s), u^{\prime \prime}(s)\right) d s .
$$

Hence

$\frac{b}{2}\left[\int_{0}^{1}(1-s)^{2} f\left(s, u(s), u^{\prime}(s), u^{\prime \prime}(s)\right) d s-\frac{1}{\eta^{3}} \int_{0}^{\eta}(\eta-s)^{3} f\left(s, u(s), u^{\prime}(s), u^{\prime \prime}(s)\right) d s\right]>0$.

Therefore $\frac{b}{2} I>0$. So condition $\left(H_{3}\right)$ is satisfied.

Thus, all the conditions of Theorem 3.1 are satisfied, which implies that the boundary value problem (3.23) - 3.24 has at least one solution $u \in C^{2}[0,1]$.

Acknowledgments. The author sincerely thanks the editor and reviewers for their valuable suggestions and useful comments to improve the manuscript.

\section{REFERENCES}

[1] N. Bouteraa and S. Benaicha, Nonlinear boundary value problems for higher-order ordinary differential equation at resonance, Romanian Journal of Mathematic and Computer Science. 2018. Vol 8, Issue 2 (2018), p. 83-91.

[2] N. Bouteraa, S. Benaicha, Existence of solutions for third-order three-point boundary value problem, Mathematica. 60 (83),N.01, 2018, pp. 21-31.

[3] Z. Du, W. Ge, X. Lin, Nonlocal boundary value problem of higher order ordinary differential equations at resonance, Rocky Mountain J. Math. 36, no. 5 (2006), 1471-1486.

[4] H. Djourdem and S. Benaicha, Existence of positive solutions for a nonlinear three-point boundary value problem with integral boundary conditions, Acta Math. Univ. Comenianae. Vol 87, 2(2018), pp 167-177.

[5] W. Feng and J. R. L. Webb, Solvability of three-point boundary value problem at resonance, Nonl. Anal. Theory Methods and Appl. 30 (1997), 3227-3238.

[6] C. P. Gupta, Solvability of a three-point nonlinear boundary value problem for a secondorder ordinary differential equations, J. Math. Anal. Appl. 168 (1998), 540-551.

[7] A. Guezane-Lakoud, A. Frioui, Third-order boundary value problem with integral condition at resonance, Theory and Application of Mathematics and Comput Science. 3 (1)(2013), 56-64.

[8] W. H. Jiang, Y. P. Guo and J. Qiu, Solvability of 2n-order m-point boundary value problem at resonance, Appl. Math. Mech. (English Ed). 28, no. 9(2007), 1219-1226.

[9] G. Karakostas and P. Ch. Tsamatos, On a nonlocal boundary value problem at resonance, J. Math. Anal. Appl. 259, no. 1, (2001), 209-218.

[10] E. R. Kaufmann, A third-order nonlocal boundary value problem at resonance, E. J. Qualitative Theory of Diff. Equ. (1) (2009), 1-11.

[11] X. Liu, J. Qiu, Y. Guo, Three positive solutions for second-order $m$-point boundary value problems, Appl. Math. Comput. 156, no. 3 (2004), 733-742

[12] Y. Lin, Z. D and F. Meng, A note on third-order multi-point boundary value problem at resonance, Math. Nachr. 284 (13) (2011), 1690-1700.

[13] J. Mawhin, Tobological degree Methods in Nonlinear Boundary Value Problems, NSF-CBMS Regional Conference Series in Mathematics,40, Amer. Math. Soc., Providence, RI, 1979.

[14] R. Ma, Multiplicity results for a third order boundary value problem at resonance, Nonl. Anal. 32 (2005), 493-499. 
NOUREDDINE BOUTERAA AND SLIMANE BENAICHA

[15] F. Meng and Z. Du, Solvability of a second order multi-point boundary value problems at resonance, Appl. Math. Comput. 208, (2010), 23-30.

[16] B. Przeradzki and R. Stanczy, Solvability of multi-point boundary value problems at resonance, J. Math. Anal. Appl. 264 (2) (2001), 253-261.

[17] H. Z. Wang, Y. Li, Neumann boundary value problems for second-order ordinary differential equations across resonance, SIAM. J. Contro. Optim. 33 (1995), 1312-1325.

[18] J. R. L. Webb, M. Zima, Multiple positive solutions of resonant and non-resonant nonlocal boundary value problems, Nonl. Anal. 71 (2009), 1369-1378.

[19] C. Xue, Z. Du and W. Ge, Solutions of M-point boundary value problems of third-order ordinary differential equations at resonance, J. Appl. Math. Comput. 17 (2005), No. 1-2, 229-244.

[20] A. Yong, B. Sun and W. Ge, Existence of positive solutions for self-adjoint boundary value problems with integral boundary condition at resonance, Electron. J. Differ. Equ. (2011), 11, $1-8$.

[21] H. Zhang. W. Liu and T. Chen, Exsistence of solutions for three-point boundary value problem. J. Appl. Math. Infor. 27(5-6) (2009), 35-51.

[22] X. Zhang, M. Feng and W. Ge, Existence result of second-order differential equations with integral boundary conditions at resonance, J. Math. Appl. 353 (1) (2009), 311-319.

Noureddine BouteraA,

Laboratory of Fundamental and Applied Mathematics of Oran (LMFAO), University of Oran 1, AB, 31000, Algeria

Email address: bouteraa-27@hotmail.fr

Slimane Benaicha,

Laboratory of Fundamental and Applied Mathematics of Oran (LMFAO), University of Oran 1, AB, 31000, Algeria

Email address: slimanebenaicha@yahoo.fr 